\title{
Educação popular, promoção da saúde e envelhecimento ativo: uma revisão bibliográfica integrativa
}

\author{
Popular education, health promotion and active aging: \\ an integrative literature review
}

Elza Maria de Souza (https://orcid.org/0000-0002-7923-9908) ${ }^{1}$

Daiane Pereira Pires Silva (https://orcid.org/0000-0001-7400-2410) ${ }^{2}$

Alexandre Soares de Barros (https://orcid.org/0000-0003-0063-3409) ${ }^{3}$

${ }^{1}$ Departamento de Saúde Coletiva, Faculdade de Saúde, Universidade de Brasília. Campus Darcy Ribeiro, Asa Norte. 70910900 Brasília DF Brasil. elzacerrado@gmail.com

${ }^{2}$ Escola Superior de Ciências da Saúde, Secretaria de Saúde do Distrito Federal. Brasília DF Brasil.

${ }^{3}$ Instituto Butantan. São Paulo SP Brasil.

\begin{abstract}
Population ageing is a global phenomenon and requires actions to promote well-being and prevent illnesses and unnecessary hospital admissions. The objective of this study was to identify education and health promotion actions aimed at promoting active aging. An integrative literature review was conducted of relevant articles written in Portuguese, English and Spanish published between 2005 and August 2018 using the following electronic databases and virtual libraries: Lilacs, MEDLINE, SciELO, and BVS. The initial search resulted in 2,069 articles, of which 33 met the inclusion criteria. The analysis showed that the actions identified by the review promoted the adoption of healthy habits and participation of older people, characterizing them as actions that promote active aging. However, the actions were limited almost exclusively to this age group, which may lead to age segregation, and focused on old age rather than adopting a life course perspective of active aging. Despite the importance of these actions, only 11 were evaluated, suggesting that the evaluation of education and health promotion actions to demonstrate effectiveness and promote replication in other locations or services is not very common practice.
\end{abstract}

Key words Popular health education, Health promotion, Active aging, Public health
Resumo O envelhecimento populacional é um fenômeno mundial e requer ações que propiciem bem-estar e previnam agravos e hospitalizações evitáveis. O propósito deste artigo foi identificar ações educativas e de promoção de saúde voltadas ao envelhecimento ativo. Trata-se de uma revisão bibliográfica integrativa de estudos publicados no ano de 2005 a agosto de 2018 nas bases de dados Lilacs e Medline, e nas bibliotecas virtuais SciE$L O$ e BVS em português, inglês e espanhol. Foram encontrados 2.069 estudos sobre os temas, sendo selecionados 33 depois de aplicados os critérios de inclusão. A observação mostrou que as ações identificadas promovem a adoção de hábitos saudáveis e a participação dos idosos, caracterizando-as como promotoras do envelhecimento ativo. No entanto, observam-se que estão limitadas ao segmento de idosos, o que pode favorecer a segregação etária, além de considerar o envelhecimento a partir da terceira idade e não um processo contínuo da vida. Das ações aqui evidenciadas, embora importantes, apenas onze delas foram avaliadas, o que sugere que a avaliação ainda não está sedimentada nos processos de intervenções de educação e promoção da saúde para mostrar efetividade e favorecer a replicação em outros locais ou serviços.

Palavras-chave Educação popular em saúde, Promoção da saúde, Envelhecimento ativo, Saúde coletiva 


\section{Introdução}

O envelhecimento populacional é um fenômeno mundial iniciado nos países de alta renda e que vem crescendo nos países de média e baixa renda, dentre eles o Brasil. Embora desejável e represente uma conquista da humanidade, esse crescimento traz implicações sociais, econômicas, políticas e de saúde ${ }^{1,2}$. As mudanças demográficas mais notáveis têm ocorrido nas idades extremas, com redução da população com menos de 15 e aumento das pessoas de 65 anos ou mais, que deixaram de ser 5,5\%, em 2000 e passarão a ser $10,7 \%$ em $2025,18,7 \%$ em 2030 e $32,9 \%$ em $2060^{3,4}$. Isso levará a uma mudança na Razão de Dependência dos Idosos (RDI) estabelecida pela razão do número de idosos sobre a população considerada produtiva ${ }^{5}$. A RDI será quadruplicada no período dos anos de 2000 a 2050, fazendo com que seja necessário adequar as políticas públicas ${ }^{5}$, visto que, com o aumento da população idosa, ocorrem mais aposentadorias e menos arrecadação para o sistema previdenciário. Essas alterações demográficas também afetam o perfil epidemiológico da população e modificam os indicadores de morbimortalidade ${ }^{3,4}$, com mudanças nos padrões das doenças que ocorrem mais em determinada população por um determinado período.

Devido às necessidades e vulnerabilidades que a população idosa apresenta, políticas públicas como o Estatuto do Idoso ${ }^{6}$, a Política Nacional de Saúde do idoso ${ }^{7}$ e a Política Nacional da pessoa Idosa $^{8}$ surgiram para regulamentar os direitos dos idosos, estimulando sua autonomia, integração e participação efetiva na sociedade, dentre eles o direito à vida e à saúde, por meio da prevenção de agravos, promoção, proteção e recuperação da saúde e um envelhecimento em condições de dignidade ${ }^{6}$. Embora esses direitos estejam bem delineados, poucas pessoas no Brasil atingem a velhice gozando os benefícios nelas preconizados. Dessa forma, as políticas fomentam, mas não garantem suas prerrogativas.

Embora grande parte dos estudos sobre envelhecimento populacional aborde principalmente a questão das implicações para a saúde pública, existem vários movimentos nacionais e internacionais que enfatizam o papel social do idoso $\mathrm{e}^{9}$ promovem ações de educação popular e promoção da saúde que favorecem o envelhecimento ativo.

A Educação em Saúde (ES), entendida a partir de vários conceitos ${ }^{10,11}$ é um processo que contribui para aprofundar o conhecimento no que se refere à saúde. No entanto, essa tem sido exercida principalmente de forma vertical, com vistas à modificação de comportamentos em saúde. Muitas responsabilizando unicamente as pessoas pela sua condição de saúde, sem considerar vários fatores e determinantes sociais que impedem a adoção de hábitos salutares por falta das condições estruturais necessárias para tal.

Com a adoção da prática da Educação Popular em Saúde (EPS), termo trazido da Educação Popular, aprimorado pelo educador Paulo Frei$\mathrm{re}^{12,13}$ a partir de 1960 , foi iniciada uma nova fase na Educação em Saúde. A EPS se estruturou a partir de uma prática pedagógica junto, e não para, à população, com o intuito de aumentar a autonomia desta, porém de forma participativa ${ }^{12}$. A EPS valoriza o conhecimento dos usuários, assim como seus saberes populares, e privilegia a horizontalidade relacional entre os profissionais de saúde e a comunidade com seus movimentos sociais locais. É um processo político-pedagógico que transforma e liberta o indivíduo e a coletividade $^{12-14}$.

A promoção da saúde, definida pela Carta de Ottaw $^{15} \mathrm{e}$ exaustivamente utilizado na literatura do campo da saúde, traz a ideia de empoderamento ao preconizar que é um processo que propicia às pessoas e à comunidade a possibilidade de exercer controle sobre sua saúde, listando uma série de fatores necessários à vida saudável e enfatizando a importância da participação social e a integração intersetorial para a sua prática e alcance. Esse conceito, mais uma vez, encontra vários obstáculos à sua abordagem, visto que a saúde, além de ser um evento multifatorial, depende para o seu alcance, de mudanças estruturais básicas como renda, habitação, emprego, educação, entre outros, que estão cada vez mais difíceis de atingir com modelos econômicos neoliberais e em condições de ameaças à democracia como vem acontecendo no Brasil ultimamente.

Nessa linha de aprimoramento e busca de melhor estado de saúde, e considerando a necessidade de atenção à população idosa, a Organização Mundial de Saúde lançou em 2005 a perspectiva de envelhecimento ativo, definido como o processo de otimização das oportunidades de saúde, participação e segurança, com o objetivo de melhorar a qualidade de vida à medida que as pessoas ficam mais velhas. A palavra "ativo" refere-se à participação contínua nas questões sociais, econômicas, culturais, espirituais e civis, e não somente à capacidade de estar fisicamente ativo ou de fazer parte da força de trabalho. $\mathrm{O}$ envelhecimento ativo tem como objetivo o aumen- 
to da expectativa de vida ativa, com qualidade independente da idade ${ }^{16}$.

Verifica-se como essas três abordagens estão relacionadas e como trazem, implícita ou explicitamente, a participação como forma de empoderamento ${ }^{15}$, condição fundamental para usufruir a plenitude da saúde. Essa interdependência faz com que alguns autores considerem a EPS como uma modalidade de promoção de saúde ${ }^{17}$ enquanto que para outros é uma estratégia para promover saúde ${ }^{18,19}$, mas as duas contribuem para o envelhecimento ativo, e este, por sua vez, pode facilitar tanto uma quanto a outra, uma vez que as pessoas em qualquer idade podem contribuir para a efetivação de ambas, resultando um círculo virtuoso para o bem-estar individual e coletivo.

Para que um idoso possa seguir uma vida caracterizada como ativa, é levado em consideração sua capacidade funcional, seu grau de independência e autonomia. Assim, as políticas públicas, os programas e os projetos destinados ao bem-estar dessa parcela da população devem buscar aprimorar, manter ou recuperar esses fatores. Prerrogativas já destacadas no Estatuto do Idoso $^{6}$ e nas políticas de saúde do idoso ${ }^{7,8}$. Tais documentos enfatizam a importância dos idosos serem vistos como e terem oportunidades para serem agentes engajados, principalmente nas questões a eles relacionadas. No entanto, a participação social tem sido objeto de vários discursos e documentos oficiais, mas isso implica, entre outros fatores, a divisão de poderes e, portanto, sua prática ainda é dificultada.

Vale ressaltar que os hábitos, as atitudes e os comportamentos adquiridos na infância e na juventude influenciam a qualidade da velhice. Portanto, as práticas saudáveis e a participação social devem ser estimuladas ao longo da vida para serem perpetuadas na velhice. A população idosa, com o seu aumento crescente, deve estar atenta e consciente do poder que tem, visto que esse segmento está se tornando importante para interesses de diversas naturezas e pode ser uma das forças políticas do País.

Desse modo, e considerando-se o atual processo de envelhecimento da população brasileira, os riscos de agravos à saúde e as demandas por práticas emancipadoras, são importantes para tornar a velhice uma fase prazerosa e atuante. Assim, o propósito deste artigo foi identificar ações educativas e de promoção de saúde voltadas ao envelhecimento ativo.

\section{Método}

Trata-se de uma revisão bibliográfica integrativa, método específico de pesquisa que permite sintetizar e avaliar criticamente evidências teóricas e empíricas de determinado evento. Possibilita que o seu produto final apresente o estado atual do conhecimento do tema investigado, a implementação de intervenções efetivas na atenção à saúde, a redução de custos, a construção do conhecimento em saúde, bem como o aprimoramento das práticas e políticas públicas de saúde ${ }^{20,21}$. Para este estudo foram seguidos os passos preconizados para a realização desse tipo de estudo ${ }^{20}$ seguindo-se a pergunta: que ações educativas e de promoção da saúde estão sendo desenvolvidas para proporcionar o envelhecimento ativo? Foi considerado o período de 2005 a agosto de 2018, em virtude do lançamento do documento oficial da Organização Mundial da Saúde sobre o envelhecimento ativo em 2005, e utilizadas, para a busca de artigos, as bases de dados: Literatura Latino-Americana e do Caribe em Ciências da Saúde (Lilacs) e Medical Literature Analysis and Retrieval System Online (Medline) e as bibliotecas virtuais: Scientific Electronic Library Online (SciELO) e Biblioteca Virtual em Saúde (BVS). Foram utilizadas as combinações dos descritores: "educação em saúde" "idosos" e promoção da saúde, e as palavras-chave: "envelhecimento ativo" e "educação popular em saúde" que não constam nos Descritores em Ciências da Saúde (DeCS), juntamente com o operador booleano "AND". Utilizaram-se esses mesmos descritores e palavras-chave em inglês e espanhol, com o operador booleano "AND" como detalhado na Figura 1.

A seleção inicial dos artigos ocorreu mediante a leitura dos títulos e resumos, separando-se os relacionados com o objetivo do estudo. Foram incluídos artigos em português, espanhol e inglês disponíveis na íntegra e que abordavam a temática de educação com ênfase na EPS e aqueles relativos à promoção da saúde (PS) voltada ao envelhecimento ativo. Foram excluídos os artigos de revisão bibliográfica, teses e, no que se refere aos artigos duplicados, apenas um foi considerado para o estudo. A leitura integral dos artigos foi realizada utilizando-se os critérios de promoção do envelhecimento ativo, mesmo que este não estivesse explícito no texto, considerando-se os que continham ações e seguiam princípios básicos da educação popular em saúde e promoção da saú- 
Bases de dados

SciELO, Lilacs, BVS e Medline

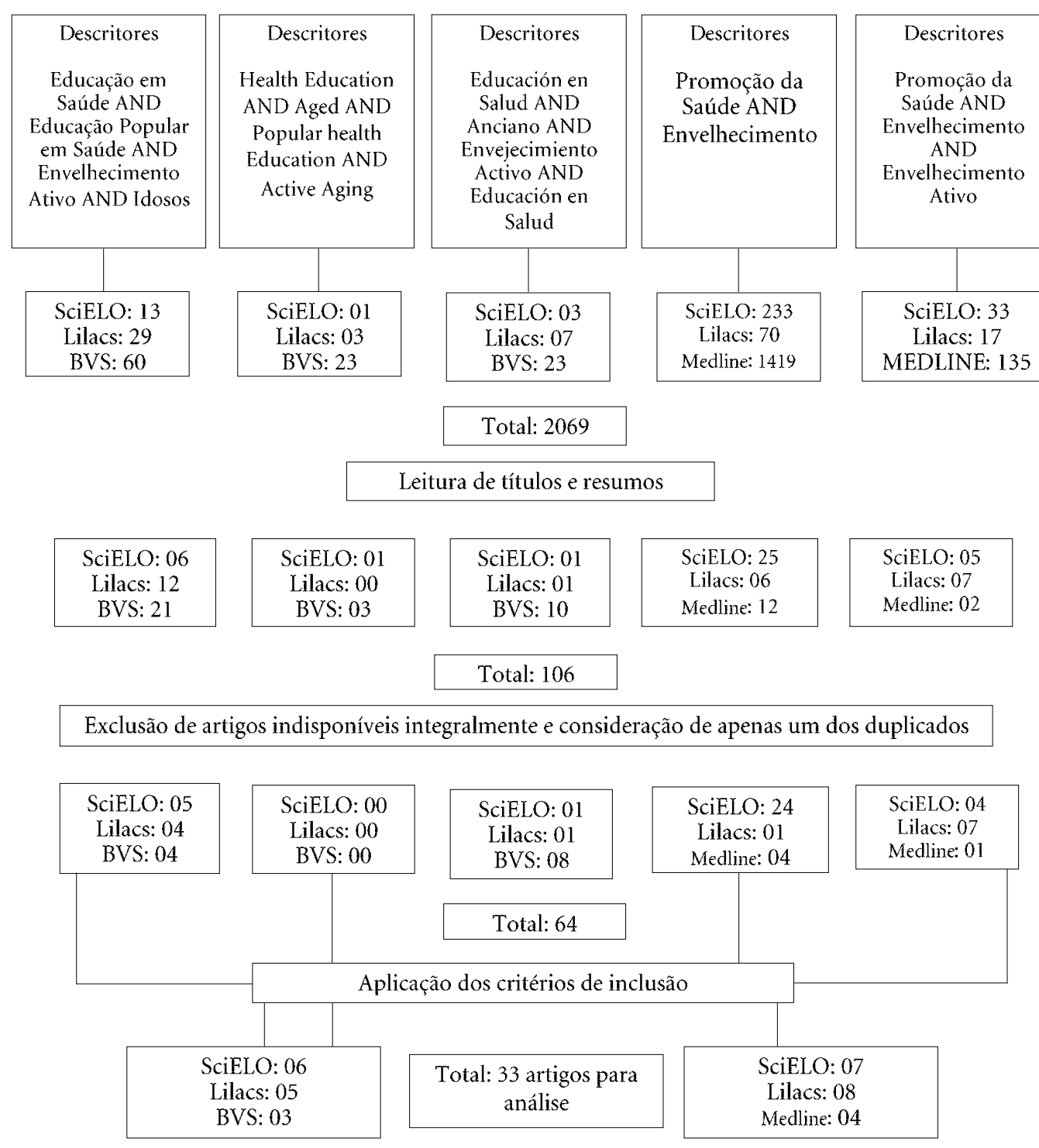

Figura 1. Desenho esquemático da metodologia desenvolvida para busca e seleção de artigos nas bases de dados.

Fonte: Desenvolvido pelo co-autor do artigo, Alexandre Soares de Barros.

de, tais como a participação ativa para o empoderamento dos participantes, intersetorialidade e que promoviam a autonomia, a independência e a capacidade funcional das pessoas participantes.

\section{Resultados e discussão}

Foram encontrados inicialmente 2069 artigos dos quais foram selecionados 33 que estavam de acordo os critérios de inclusão estabelecidos (Figura 1).

Os resultados foram sistematizados em uma matriz detalhadas no Quadro 1. 
Quadro 1. Publicações de educação popular e promoção da saúde voltadas ao envelhecimento ativo de acordo com autoria, ano de publicação e local do estudo, título, objetivos e tipo de ação desenvolvida.

\begin{tabular}{|c|c|c|c|c|}
\hline Autores & $\begin{array}{l}\text { Ano de publicação, } \\
\text { local da pesquisa e } \\
\text { local da ação }\end{array}$ & Título & Objetivo & Ação desenvolvida \\
\hline Assis $^{22}$ & $\begin{array}{l}\text { 2005, Rio } \\
\text { de Janeiro, } \\
\text { Ambulatório de } \\
\text { Atenção ao Idoso } \\
\text { de um Hospital } \\
\text { Universitário. }\end{array}$ & $\begin{array}{l}\text { Envelhecimento } \\
\text { ativo e promoção da } \\
\text { saúde: reflexão para } \\
\text { as ações educativas } \\
\text { com idosos. }\end{array}$ & $\begin{array}{l}\text { Oferecer uma } \\
\text { contribuição acerca do } \\
\text { sentido ético-político } \\
\text { das ações educativas } \\
\text { com idosos. }\end{array}$ & $\begin{array}{l}\text { Grupos de idosos para } \\
\text { conduzir o instrumento } \\
\text { de pesquisa e de ação } \\
\text { educativa em nível } \\
\text { individual: Avaliação } \\
\text { Multidimensional de } \\
\text { Saúde e Qualidade de } \\
\text { Vida. }\end{array}$ \\
\hline $\begin{array}{l}\text { Sancho } \\
\text { Castiello et } \\
\text { al. } .^{23}\end{array}$ & $\begin{array}{l}\text { 2006, Espanha, } \\
\text { Sociedade } \\
\text { Espanhola de } \\
\text { Geriatria e } \\
\text { Gerontologia }\end{array}$ & $\begin{array}{l}\text { Saber envejecer. } \\
\text { Prevenir la } \\
\text { dependencia. Un } \\
\text { modelo para el } \\
\text { diseño de materiales } \\
\text { didácticos. }\end{array}$ & $\begin{array}{l}\text { Descrever um projeto } \\
\text { de pesquisa-ação com } \\
\text { metodologia qualitativa } \\
\text { que visa promover o } \\
\text { envelhecimento ativo e } \\
\text { evitar dependência. }\end{array}$ & $\begin{array}{l}\text { Desenvolvimento de } \\
\text { materiais didáticos e } \\
\text { audiovisuais baseados na } \\
\text { realização de } 13 \text { grupos } \\
\text { focais com pessoas na } \\
\text { faixa etária entre } 55 \text { e } \\
80 \text { anos em } 6 \text { cidades da } \\
\text { Espanha. }\end{array}$ \\
\hline Assis et al. ${ }^{24}$ & $\begin{array}{l}\text { 2007, Rio de } \\
\text { Janeiro, Núcleo } \\
\text { de Atenção ao } \\
\text { Idoso de uma } \\
\text { Universidade da } \\
\text { Terceira Idade }\end{array}$ & $\begin{array}{l}\text { Ações educativas em } \\
\text { promoção da saúde } \\
\text { no envelhecimento: } \\
\text { a experiência do } \\
\text { núcleo de atenção } \\
\text { ao idoso da UNATI/ } \\
\text { UERJ }\end{array}$ & $\begin{array}{l}\text { Apresentar um projeto } \\
\text { de extensão e apontar } \\
\text { sua contribuição para } \\
\text { um modelo de atenção e } \\
\text { de formação profissional } \\
\text { pautado no cuidado } \\
\text { integral e na promoção } \\
\text { da saúde. }\end{array}$ & $\begin{array}{l}\text { Atividades diversas em } \\
\text { grupos: encontros com } \\
\text { a Saúde, Roda da Saúde } \\
\text { e produção de materiais } \\
\text { educativos (folders e } \\
\text { murais). }\end{array}$ \\
\hline $\begin{array}{l}\text { Martins et } \\
\text { al. }^{25}\end{array}$ & $\begin{array}{l}\text { 2007, Florianópolis, } \\
\text { Ambulatório } \\
\text { de Referência } \\
\text { Estadual. }\end{array}$ & $\begin{array}{l}\text { Educação em saúde } \\
\text { como suporte para a } \\
\text { qualidade de vida de } \\
\text { grupos da terceira } \\
\text { idade }\end{array}$ & $\begin{array}{l}\text { Conhecer as } \\
\text { necessidades de } \\
\text { educação em saúde dos } \\
\text { idosos que frequentam } \\
\text { grupos de terceira idade. }\end{array}$ & $\begin{array}{l}\text { Atividades e técnicas } \\
\text { grupais, questionários e } \\
\text { observação participante } \\
\text { sobre diabetes, } \\
\text { hipertensão arterial, } \\
\text { osteoporose, artrite e } \\
\text { artrose e alimentação } \\
\text { equilibrada }\end{array}$ \\
\hline $\begin{array}{l}\text { Alencar et } \\
\text { al. }^{26}\end{array}$ & $\begin{array}{l}\text { 2008, Piauí, } \\
\text { Universidade da } \\
\text { Terceira Idade }\end{array}$ & $\begin{array}{l}\text { Os aportes } \\
\text { sócio-políticos } \\
\text { da educação } \\
\text { nutricional na } \\
\text { perspectiva de um } \\
\text { envelhecimento } \\
\text { saudável }\end{array}$ & $\begin{array}{l}\text { Refletir sobre as } \\
\text { vivências de sala de aula } \\
\text { com idosos de uma } \\
\text { universidade da terceira } \\
\text { idade, a partir de uma } \\
\text { oficina ludo pedagógica. }\end{array}$ & $\begin{array}{l}\text { Encontros semanais com } \\
\text { oficinas ludo pedagógicas } \\
\text { sobre nutrição, saúde } \\
\text { e envelhecimento com } \\
\text { idosos que frequentaram } \\
\text { um programa } \\
\text { universitário da terceira } \\
\text { idade. }\end{array}$ \\
\hline $\begin{array}{l}\text { Bernardo et } \\
\text { al. }{ }^{27}\end{array}$ & $\begin{array}{l}\text { 2009, Rio de } \\
\text { Janeiro, Núcleo de } \\
\text { Atenção ao Idoso } \\
\text { da Universidade } \\
\text { Aberta da Terceira } \\
\text { Idade/ } \\
\text { UERJ }\end{array}$ & $\begin{array}{l}\text { A saúde no } \\
\text { diálogo com a } \\
\text { vida cotidiana: } \\
\text { a experiência do } \\
\text { trabalho educativo } \\
\text { com idosos no } \\
\text { grupo roda da saúde }\end{array}$ & $\begin{array}{l}\text { Apresentar a proposta } \\
\text { metodológica do grupo } \\
\text { "Roda da Saúde" e } \\
\text { apontar alguns dados de } \\
\text { avaliação do trabalho, a } \\
\text { partir dos registros de } \\
\text { suas atividades. }\end{array}$ & $\begin{array}{l}\text { Grupos educativos } \\
\text { caracterizados como } \\
\text { "chá da tarde", onde a } \\
\text { dinâmica dos encontros } \\
\text { buscou estimular a } \\
\text { reflexão e a produção } \\
\text { coletiva sobre temas } \\
\text { relacionados à saúde e } \\
\text { qualidade de vida. }\end{array}$ \\
\hline
\end{tabular}


Quadro 1. Publicações de educação popular e promoção da saúde voltadas ao envelhecimento ativo de acordo com autoria, ano de publicação e local do estudo, título, objetivos e tipo de ação desenvolvida.

\begin{tabular}{|c|c|c|c|c|}
\hline Autores & \begin{tabular}{|c|} 
Ano de publicação, \\
local da pesquisa e \\
local da ação
\end{tabular} & Título & Objetivo & Ação desenvolvida \\
\hline Mazo et al. ${ }^{28}$ & $\begin{array}{l}\text { 2009, Florianópolis, } \\
\text { Grupo de Estudos } \\
\text { da Terceira } \\
\text { Idade (GETI) da } \\
\text { Universidade do } \\
\text { Estado de Santa } \\
\text { Catarina }\end{array}$ & $\begin{array}{l}\text { Do diagnóstico } \\
\text { à ação: grupo de } \\
\text { estudos da terceira } \\
\text { idade: alternativa } \\
\text { para a promoção } \\
\text { do envelhecimento } \\
\text { ativo }\end{array}$ & $\begin{array}{l}\text { Descrever o } \\
\text { funcionamento das } \\
\text { ações de promoção } \\
\text { de atividade física } \\
\text { de um programa de } \\
\text { extensão para subsidiar } \\
\text { programas futuros. }\end{array}$ & $\begin{array}{l}\text { Ações de atividade física } \\
\text { do Grupo de Estudos da } \\
\text { Terceira Idade (GETI). }\end{array}$ \\
\hline $\begin{array}{l}\text { Kuczmarksi, } \\
\text { Cotugna }^{29}\end{array}$ & $\begin{array}{l}\text { 2009, Delaware } \\
\text { - EUA, Centro } \\
\text { especializado em } \\
\text { idosos denominado } \\
\text { "Wilmington } \\
\text { Senior Center" }\end{array}$ & $\begin{array}{l}\text { Outcome evaluation } \\
\text { of a 3-year senior } \\
\text { health and wellness } \\
\text { initiative }\end{array}$ & $\begin{array}{l}\text { Descrever o } \\
\text { desenvolvimento } \\
\text { e implementação } \\
\text { da metodologia de } \\
\text { avaliação e resultados } \\
\text { de uma iniciativa } \\
\text { multidisciplinar de } \\
\text { saúde e bem-estar. }\end{array}$ & $\begin{array}{l}\text { Realizados } 11 \text { programas } \\
\text { multidisciplinares que } \\
\text { abordaram saúde e bem- } \\
\text { estar ao longo de } 3 \text { anos } \\
\text { com idosos. }\end{array}$ \\
\hline $\begin{array}{l}\text { Combinato } \\
\text { et al. } .^{30}\end{array}$ & $\begin{array}{l}\text { 2010, Paranaíba - } \\
\text { Mato Grosso do } \\
\text { Sul, Atenção Básica } \\
\text { em Saúde }\end{array}$ & $\begin{array}{l}\text { Grupos de conversa: } \\
\text { saúde da pessoa } \\
\text { idosa na estratégia } \\
\text { saúde da família. }\end{array}$ & $\begin{array}{l}\text { Desenvolver um } \\
\text { processo grupal de } \\
\text { promoção à saúde com } \\
\text { pessoas idosas, tendo em } \\
\text { vista o envelhecimento } \\
\text { ativo e a qualidade de } \\
\text { vida dessa população. }\end{array}$ & $\begin{array}{l}\text { Grupos de conversas } \\
\text { fechados, com } \\
\text { periodicidade } \\
\text { semanal, formados } \\
\text { predominantemente por } \\
\text { mulheres. }\end{array}$ \\
\hline $\begin{array}{l}\text { Firmino et } \\
\text { al. }{ }^{31}\end{array}$ & $\begin{array}{l}\text { 2010, João Pessoa, } \\
\text { Atenção Básica em } \\
\text { Saúde }\end{array}$ & $\begin{array}{l}\text { Educação popular } \\
\text { e promoção da } \\
\text { saúde do idoso: } \\
\text { reflexões a partir } \\
\text { de uma experiência } \\
\text { de extensão } \\
\text { universitária com } \\
\text { grupos de idosos em } \\
\text { João Pessoa-PB }\end{array}$ & $\begin{array}{l}\text { Relatar experiência } \\
\text { visando explanar } \\
\text { os aprendizados, } \\
\text { dificuldades e } \\
\text { inquietações que } \\
\text { permearam a } \\
\text { experiência vivenciada } \\
\text { pelos participantes de } \\
\text { um projeto de extensão } \\
\text { universitária. }\end{array}$ & $\begin{array}{l}\text { Atividades de educação } \\
\text { em saúde voltadas à } \\
\text { nutrição com grupos de } \\
\text { idosos. }\end{array}$ \\
\hline Paiva et al. ${ }^{32}$ & $\begin{array}{l}\text { 2010, São Paulo, } \\
\text { Universidade } \\
\text { Estadual Paulista }\end{array}$ & $\begin{array}{l}\text { Dança e } \\
\text { envelhecimento: } \\
\text { uma parceria em } \\
\text { movimento }\end{array}$ & $\begin{array}{l}\text { Apresentar o programa } \\
\text { estudado, que } \\
\text { desenvolve um conjunto } \\
\text { de atividades destinadas } \\
\text { às pessoas com mais de } \\
\text { sessenta anos. }\end{array}$ & $\begin{array}{l}\text { Aulas de dança dentro do } \\
\text { Programa de Atividade } \\
\text { Física para a Terceira } \\
\text { Idade - PROFIT realizado } \\
\text { na UNESP. }\end{array}$ \\
\hline $\begin{array}{l}\text { Tahan, } \\
\text { Carvalho }^{33}\end{array}$ & $\begin{array}{l}\text { 2010, Ribeirão } \\
\text { Preto-São Paulo, } \\
\text { Atenção Básica em } \\
\text { Saúde }\end{array}$ & $\begin{array}{l}\text { Reflexões de Idosos } \\
\text { Participantes } \\
\text { de Grupos de } \\
\text { Promoção de } \\
\text { Saúde Acerca do } \\
\text { Envelhecimento e da } \\
\text { Qualidade de Vida. }\end{array}$ & $\begin{array}{l}\text { Analisar e refletir sobre } \\
\text { as percepções dos } \\
\text { idosos em relação à sua } \\
\text { qualidade de vida, com } \\
\text { vistas à integralidade } \\
\text { da assistência, após } \\
\text { a adesão à grupos de } \\
\text { promoção de Saúde. }\end{array}$ & $\begin{array}{l}\text { Realização grupos } \\
\text { abertos de atividades } \\
\text { de artesanato, dança, } \\
\text { descontração e saúde } \\
\text { utilizando-se as } \\
\text { atividades lúdicas e de } \\
\text { lazer. }\end{array}$ \\
\hline
\end{tabular}


Quadro 1. Publicações de educação popular e promoção da saúde voltadas ao envelhecimento ativo de acordo com autoria, ano de publicação e local do estudo, título, objetivos e tipo de ação desenvolvida.

\begin{tabular}{|c|c|c|c|c|}
\hline Autores & $\begin{array}{c}\text { Ano de publicação, } \\
\text { local da pesquisa e } \\
\text { local da ação }\end{array}$ & Título & Objetivo & Ação desenvolvida \\
\hline $\begin{array}{l}\text { Souza, } \\
\text { Grundi }^{34}\end{array}$ & $\begin{array}{l}\text { 2011, Ceilândia- } \\
\text { Distrito Federal, } \\
\text { Escola de ensino } \\
\text { fundamental }\end{array}$ & $\begin{array}{l}\text { Intergenerational } \\
\text { integration, social } \\
\text { capital and health: } \\
\text { a theoretical } \\
\text { framework and } \\
\text { results from a } \\
\text { qualitative study }\end{array}$ & $\begin{array}{l}\text { Avaliar atividades } \\
\text { intergeracionais em } \\
\text { uma escola e descrever o } \\
\text { arcabouço teórico para } \\
\text { explicar as mudanças } \\
\text { observadas. }\end{array}$ & $\begin{array}{l}\text { Intervenção } \\
\text { intergeracional onde } \\
\text { idosos compartilhavam } \\
\text { história de vida com } \\
\text { adolescentes, em } \\
\text { uma escola de ensino } \\
\text { fundamental, avaliada } \\
\text { por meio de grupos e } \\
\text { focais com os dois grupos } \\
\text { etários }\end{array}$ \\
\hline $\begin{array}{l}\text { Wichmann } \\
\text { et al. } .^{35}\end{array}$ & $\begin{array}{l}\text { 2011, Santa Cruz } \\
\text { do Sul - Rio } \\
\text { Grande do Sul, } \\
\text { Clínica-escola da } \\
\text { Universidade de } \\
\text { Santa Cruz do Sul }\end{array}$ & $\begin{array}{l}\text { Promoção do } \\
\text { envelhecimento } \\
\text { saudável: adoção } \\
\text { de uma prática } \\
\text { multidisciplinar na } \\
\text { atenção à saúde do } \\
\text { idoso (UNISC) } \\
\end{array}$ & $\begin{array}{l}\text { Relatar a experiência das } \\
\text { atividades de projeto de } \\
\text { extensão universitária, } \\
\text { socializando a prática } \\
\text { multiprofissional e } \\
\text { interdisciplinar que nele } \\
\text { ocorre. }\end{array}$ & $\begin{array}{l}\text { Grupos de idosos para } \\
\text { discussão de temas } \\
\text { relacionados à saúde no } \\
\text { envelhecimento com } \\
\text { diversas atividades. }\end{array}$ \\
\hline $\begin{array}{l}\text { Andrade PT } \\
\text { et al. }{ }^{36}\end{array}$ & $\begin{array}{l}\text { 2012, Ouro } \\
\text { Preto-Minas } \\
\text { Gerais, Espaço de } \\
\text { convivência da } \\
\text { comunidade. }\end{array}$ & $\begin{array}{l}\text { Projeto conviver: } \\
\text { estímulo à } \\
\text { convivência entre } \\
\text { idosos do Catete, } \\
\text { Ouro Preto, MG. }\end{array}$ & $\begin{array}{l}\text { Descrever as } \\
\text { experiências do projeto } \\
\text { de convivência em } \\
\text { grupos com idosos. }\end{array}$ & $\begin{array}{l}\text { Oficinas e encontros com } \\
\text { temas relacionados à } \\
\text { saúde. }\end{array}$ \\
\hline Costa et al. ${ }^{37}$ & $\begin{array}{l}\text { 2012, Patos- } \\
\text { Paraíba, Clínica } \\
\text { Escola de uma } \\
\text { Instituição de } \\
\text { Ensino Superior }\end{array}$ & $\begin{array}{l}\text { Educação em } \\
\text { saúde: estratégia } \\
\text { de promoção da } \\
\text { qualidade de vida na } \\
\text { terceira idade }\end{array}$ & $\begin{array}{l}\text { Investigar se o nível } \\
\text { de qualidade de vida } \\
\text { da terceira idade é } \\
\text { influenciado pelo } \\
\text { ensino de exercícios } \\
\text { psicomotores como } \\
\text { estratégia de educação } \\
\text { em saúde. }\end{array}$ & $\begin{array}{l}\text { Prática de exercícios } \\
\text { cinético-funcionais } \\
\text { com idosos } 2 \text { vezes por } \\
\text { semana, utilizando-se a } \\
\text { metodologia pré-teste- } \\
\text { pós-teste }\end{array}$ \\
\hline $\begin{array}{l}\text { Patrocínio, } \\
\text { Todaro }^{38}\end{array}$ & $\begin{array}{l}\text { 2012, Campinas - } \\
\text { São Paulo, Atenção } \\
\text { Básica em Saúde }\end{array}$ & $\begin{array}{l}\text { Programa de } \\
\text { educação para um } \\
\text { envelhecimento } \\
\text { saudável. }\end{array}$ & $\begin{array}{l}\text { Implementar e } \\
\text { avaliar um programa } \\
\text { educacional para o } \\
\text { envelhecimento ativo. }\end{array}$ & $\begin{array}{l}\text { Encontros semanais de } \\
150 \text { minutos, durante } \\
4 \text { meses com } 16 \text { idosos } \\
\text { baseado na perspectiva } \\
\text { Freireana }\end{array}$ \\
\hline $\begin{array}{l}\text { Silveira et } \\
\text { al. }^{39}\end{array}$ & $\begin{array}{l}\text { 2012, Rio } \\
\text { Grande do Sul, } \\
\text { Universidades } \\
\text { Estaduais }\end{array}$ & $\begin{array}{l}\text { Educação } \\
\text { gerontológica, } \\
\text { envelhecimento } \\
\text { humano e } \\
\text { tecnologias } \\
\text { educacionais: } \\
\text { reflexões sobre } \\
\text { velhice ativa. }\end{array}$ & $\begin{array}{l}\text { Refletir sobre o } \\
\text { envelhecimento e } \\
\text { a possibilidade de } \\
\text { participar de uma } \\
\text { educação gerontológica } \\
\text { ampliando a qualidade } \\
\text { de vida. }\end{array}$ & $\begin{array}{l}\text { Ações desenvolvidas } \\
\text { pelas Universidades que } \\
\text { ofertam programas às } \\
\text { pessoas da terceira idade. }\end{array}$ \\
\hline $\begin{array}{l}\text { Cyarto et } \\
\text { al. }^{40}\end{array}$ & $\begin{array}{l}\text { 2013, Melbourne, } \\
\text { Victoria, Australia } \\
\text { - AU }\end{array}$ & $\begin{array}{l}\text { Promoting healthy } \\
\text { ageing: development } \\
\text { of the Healthy } \\
\text { Ageing Quiz }\end{array}$ & $\begin{array}{l}\text { Projetar um recurso } \\
\text { de fácil utilização para } \\
\text { pessoas de meia-idade e } \\
\text { mais velhas que permite } \\
\text { a autoavaliação do estilo } \\
\text { de vida }\end{array}$ & $\begin{array}{l}\text { Aplicação de } \\
\text { Questionário do } \\
\text { Envelhecimento Saudável } \\
\text { (Healthy Ageing } \\
\text { Quiz) para o aumento } \\
\text { da consciência e o } \\
\text { conhecimento de como } \\
\text { envelhecer bem. }\end{array}$ \\
\hline
\end{tabular}

continua 
Quadro 1. Publicações de educação popular e promoção da saúde voltadas ao envelhecimento ativo de acordo com autoria, ano de publicação e local do estudo, título, objetivos e tipo de ação desenvolvida.

\begin{tabular}{|c|c|c|c|c|}
\hline Autores & $\begin{array}{c}\text { Ano de publicação, } \\
\text { local da pesquisa e } \\
\text { local da ação }\end{array}$ & Título & Objetivo & Ação desenvolvida \\
\hline $\begin{array}{l}\text { Patrocínio, } \\
\text { Pereira }^{41}\end{array}$ & $\begin{array}{l}\text { 2013, Campinas- } \\
\text { São Paulo, Atenção } \\
\text { Básica em Saúde }\end{array}$ & $\begin{array}{l}\text { Efeitos da educação } \\
\text { em saúde sobre } \\
\text { atitudes de idosos } \\
\text { e sua contribuição } \\
\text { para a educação } \\
\text { gerontológica. }\end{array}$ & \begin{tabular}{|l} 
Avaliar os efeitos de um \\
programa comunitário \\
de educação popular em \\
saúde para idosos sobre \\
suas atitudes em relação \\
à velhice
\end{tabular} & $\begin{array}{l}\text { Realização de } 16 \\
\text { encontros semanais de } \\
150 \text { minutos com grupos } \\
\text { de idosos para discutir } \\
\text { sobre as imagens positivas } \\
\text { e negativas relacionadas à } \\
\text { velhice. }\end{array}$ \\
\hline $\begin{array}{l}\text { Mendonça } \\
\text { et al. }{ }^{42}\end{array}$ & $\begin{array}{l}\text { 2013, Viçosa-Minas } \\
\text { Gerais, núcleo } \\
\text { de referência } \\
\text { de atendimento } \\
\text { multiprofissional a } \\
\text { idosos. }\end{array}$ & $\begin{array}{l}\text { A experiência de } \\
\text { oficinas educativas } \\
\text { com idosos: (Re) } \\
\text { pensando práticas à } \\
\text { luz do pensamento } \\
\text { Freireano. } \\
\end{array}$ & $\begin{array}{l}\text { Relatar uma experiência } \\
\text { para subsidiar a reflexão } \\
\text { sobre a prática de } \\
\text { oficinas como estratégia } \\
\text { de educação em saúde, } \\
\text { na perspectiva Freireana. }\end{array}$ & $\begin{array}{l}\text { Foram desenvolvidas } \\
\text { oficinas com idosos sobre } \\
\text { uso de medicamentos. }\end{array}$ \\
\hline $\begin{array}{l}\text { Morrow- } \\
\text { Howell et } \\
\text { al. }^{43}\end{array}$ & $\begin{array}{l}\text { 2014, Estados } \\
\text { Unidos da América, } \\
\text { Escolas. }\end{array}$ & $\begin{array}{l}\text { Volunteering } \\
\text { as a pathway to } \\
\text { productive and } \\
\text { social engagement } \\
\text { among older adults } \\
\end{array}$ & $\begin{array}{l}\text { Examinar os efeitos do } \\
\text { trabalho voluntário de } \\
\text { idosos em atividades } \\
\text { social e cívica }\end{array}$ & $\begin{array}{l}\text { Projeto onde os idosos } \\
\text { se voluntariaram para } \\
\text { realizar atividades sociais. }\end{array}$ \\
\hline Sato et al. ${ }^{44}$ & $\begin{array}{l}\text { 2014, São Paulo, } \\
\text { Laboratório } \\
\text { de Gerontologia de } \\
\text { uma Universidade. }\end{array}$ & $\begin{array}{l}\text { Programas de } \\
\text { estimulação } \\
\text { da memória e } \\
\text { funções cognitivas } \\
\text { relacionadas: } \\
\text { opiniões e } \\
\text { comportamentos } \\
\text { dos idosos } \\
\text { participantes }\end{array}$ & $\begin{array}{l}\text { Apresentar a influência } \\
\text { do programa sobre } \\
\text { a memória para } \\
\text { desempenho das } \\
\text { tarefas da vida diária } \\
\text { e da incorporação dos } \\
\text { hábitos no cotidiano }\end{array}$ & $\begin{array}{l}\text { Atividades em grupo } \\
\text { de idosos com aulas } \\
\text { expositivas e dialogadas, } \\
\text { dinâmicas grupais, } \\
\text { com estratégias de } \\
\text { memória, e reflexão sobre } \\
\text { comportamentos de vida } \\
\text { ativa e saudável. }\end{array}$ \\
\hline $\begin{array}{l}\text { Almeida et } \\
\text { al. }^{45}\end{array}$ & $\begin{array}{l}\text { 2015, Viçosa - } \\
\text { Minas Gerais, } \\
\text { Atenção Básica em } \\
\text { Saúde }\end{array}$ & $\begin{array}{l}\text { Projeto de } \\
\text { intervenção } \\
\text { comunitária "Em } \\
\text { Comum-Idade": } \\
\text { contribuições para a } \\
\text { promoção da saúde } \\
\text { entre idosos de } \\
\text { Viçosa, MG, Brasil } \\
\end{array}$ & \begin{tabular}{|l|} 
Analisar as possíveis \\
mudanças ocorridas \\
nas medidas \\
antropométricas e nos \\
níveis de aptidão física \\
funcional dos idosos \\
participantes do projeto.
\end{tabular} & $\begin{array}{l}\text { Oficinas de educação } \\
\text { alimentar e nutricional, } \\
\text { de exercício físico e lazer } \\
\text { e rodas de conversa sobre } \\
\text { temas relacionados ao } \\
\text { envelhecimento saudável } \\
\text { com avaliações da } \\
\text { intervenção. }\end{array}$ \\
\hline Massi et al. ${ }^{46}$ & $\begin{array}{l}\text { 2015, Curitiba, } \\
\text { Atenção Básica em } \\
\text { Saúde }\end{array}$ & $\begin{array}{l}\text { Linguagem e } \\
\text { envelhecimento: } \\
\text { práticas de escrita } \\
\text { autobiográfica junto } \\
\text { a idosos }\end{array}$ & $\begin{array}{l}\text { Analisar, sob a } \\
\text { perspectiva do } \\
\text { letramento, os efeitos } \\
\text { que práticas de escritas } \\
\text { autobiográficas podem } \\
\text { gerar na autonomia e } \\
\text { no bem-estar de sujeitos } \\
\text { idosos. }\end{array}$ & $\begin{array}{l}\text { Encontros semanais para } \\
\text { realização de oficinas } \\
\text { de letramento com o } \\
\text { objetivo de promover } \\
\text { o letramento de idosos } \\
\text { e discussão de variados } \\
\text { temas como velhice, } \\
\text { família, mercado de } \\
\text { trabalho, espiritualidade, } \\
\text { entre outros. }\end{array}$ \\
\hline Patrocínio ${ }^{47}$ & $\begin{array}{l}\text { 2014, São Paulo, } \\
\text { Atenção Básica em } \\
\text { Saúde }\end{array}$ & $\begin{array}{l}\text { Atividades } \\
\text { práticas para o } \\
\text { Envelhecimento } \\
\text { Ativo. }\end{array}$ & $\begin{array}{l}\text { Apresentar uma } \\
\text { série de atividades } \\
\text { práticas visando } \\
\text { ao envelhecimento } \\
\text { saudável, com base na } \\
\text { perspectiva Freireana } \\
\text { e na perspectiva do } \\
\text { envelhecimento Ativo }\end{array}$ & $\begin{array}{l}\text { Foram realizados } \\
\text { encontros com idosos } \\
\text { para a realização de } \\
\text { diversas atividades e } \\
\text { discussão de vários temas. }\end{array}$ \\
\hline
\end{tabular}


Quadro 1. Publicações de educação popular e promoção da saúde voltadas ao envelhecimento ativo de acordo com autoria, ano de publicação e local do estudo, título, objetivos e tipo de ação desenvolvida.

\begin{tabular}{|c|c|c|c|c|}
\hline Autores & $\begin{array}{c}\text { Ano de publicação, } \\
\text { local da pesquisa e } \\
\text { local da ação }\end{array}$ & Título & Objetivo & Ação desenvolvida \\
\hline Valer et al. ${ }^{48}$ & $\begin{array}{l}\text { 2015, Porto Alegre - } \\
\text { Rio Grande do Sul, } \\
\text { Atenção Básica em } \\
\text { Saúde }\end{array}$ & $\begin{array}{l}\text { O significado de } \\
\text { envelhecimento } \\
\text { saudável para } \\
\text { pessoas idosas } \\
\text { vinculadas a grupos } \\
\text { educativos. }\end{array}$ & $\begin{array}{l}\text { Descrever o significado } \\
\text { de envelhecimento } \\
\text { saudável para pessoas } \\
\text { idosas que participam de } \\
\text { grupos de educação em } \\
\text { saúde de uma UBS }\end{array}$ & $\begin{array}{l}\text { Aplicação de instrumento } \\
\text { com idosos que } \\
\text { participam de grupos de } \\
\text { educação em saúde. }\end{array}$ \\
\hline $\begin{array}{l}\text { Zanjani et } \\
\text { al. }^{49}\end{array}$ & $\begin{array}{l}\text { 2015, Estado de } \\
\text { Kentucky - EUA, } \\
\text { Locais públicos } \\
\text { diversos. }\end{array}$ & $\begin{array}{l}\text { Memory banking: } \\
\text { a life story } \\
\text { intervention for } \\
\text { aging preparation } \\
\text { and mental health } \\
\text { promotion }\end{array}$ & $\begin{array}{l}\text { Analisar a viabilidade } \\
\text { de Bancos de Memória } \\
\text { como ferramenta de } \\
\text { preparação para o } \\
\text { envelhecimento. }\end{array}$ & $\begin{array}{l}\text { Atividade onde idosos } \\
\text { contam suas histórias } \\
\text { de vida no contexto } \\
\text { do envelhecimento, } \\
\text { relatando sonhos, futuro, } \\
\text { aspirações, planos e } \\
\text { decisões. }\end{array}$ \\
\hline Costa et al. ${ }^{50}$ & $\begin{array}{l}\text { 2016, Belém - Pará, } \\
\text { Atenção Básica em } \\
\text { Saúde }\end{array}$ & $\begin{array}{l}\text { Contação de } \\
\text { história: tecnologia } \\
\text { cuidativa na } \\
\text { educação } \\
\text { permanente para } \\
\text { o envelhecimento } \\
\text { ativo. }\end{array}$ & $\begin{array}{l}\text { Avaliar a pertinência } \\
\text { e efetividade do } \\
\text { método de "contação } \\
\text { de histórias" como } \\
\text { estratégia para } \\
\text { envelhecimento ativo. }\end{array}$ & $\begin{array}{l}\text { Atividades destinadas } \\
\text { a idosos para contar } \\
\text { histórias de vida. }\end{array}$ \\
\hline $\begin{array}{l}\text { Inouye et } \\
\text { al. }^{51}\end{array}$ & $\begin{array}{l}\text { 2018, São Paulo, } \\
\text { Universidade } \\
\text { Aberta da Terceira } \\
\text { Idade }\end{array}$ & $\begin{array}{l}\text { Efeito da } \\
\text { Universidade Aberta } \\
\text { à Terceira Idade } \\
\text { sobre a qualidade de } \\
\text { vida do idoso. }\end{array}$ & $\begin{array}{l}\text { Avaliar o efeito do } \\
\text { programa Universidade } \\
\text { Aberta à Terceira Idade } \\
\text { na qualidade de vida de } \\
\text { alunos idosos. }\end{array}$ & $\begin{array}{l}\text { Entrevistas realizadas } \\
\text { com idosos no início e } \\
\text { ao final do ano letivo } \\
\text { para avaliar os efeitos } \\
\text { da educação sobre a } \\
\text { qualidade de vida. }\end{array}$ \\
\hline Massi et al. ${ }^{52}$ & $\begin{array}{l}\text { 2018, Curitiba- } \\
\text { Paraná, } \\
\text { Universidade. }\end{array}$ & $\begin{array}{l}\text { Active aging: an } \\
\text { intervention- } \\
\text { research report. }\end{array}$ & $\begin{array}{l}\text { Analisar os efeitos } \\
\text { que atividades com a } \\
\text { linguagem podem ter } \\
\text { sobre a autonomia e a } \\
\text { participação social de } \\
\text { idosos. }\end{array}$ & $\begin{array}{l}\text { Avaliação sobre os } \\
\text { efeitos que atividades } \\
\text { de linguagem sobre } \\
\text { histórias de vida tiveram } \\
\text { sobre a autonomia e a } \\
\text { participação social dos } \\
\text { idosos. }\end{array}$ \\
\hline $\begin{array}{l}\text { Mendes et } \\
\text { al. }{ }^{53}\end{array}$ & $\begin{array}{l}\text { 2018, Belém-Pará, } \\
\text { Atenção Básica em } \\
\text { Saúde }\end{array}$ & $\begin{array}{l}\text { Tecnologia } \\
\text { socioeducacional } \\
\text { de videodebate } \\
\text { para o cultivo do } \\
\text { envelhecimento } \\
\text { ativo. }\end{array}$ & $\begin{array}{l}\text { Avaliar efetividade } \\
\text { da tecnologia } \\
\text { socioeducacional } \\
\text { de videodebate } \\
\text { como estratégia ao } \\
\text { envelhecimento ativo. }\end{array}$ & $\begin{array}{l}\text { Foram realizadas } 8 \\
\text { oficinas de videodebate } \\
\text { com associação dos } \\
\text { vídeos às histórias } \\
\text { de vida e hábitos dos } \\
\text { participantes idosos. }\end{array}$ \\
\hline $\begin{array}{l}\text { Olympio, } \\
\text { Alvim }^{54}\end{array}$ & $\begin{array}{l}\text { 2018, Vitória- } \\
\text { Espírito Santo, } \\
\text { Universidade } \\
\text { Aberta da Terceira } \\
\text { Idade }\end{array}$ & $\begin{array}{l}\text { Board games: } \\
\text { gerotechnology } \\
\text { in nursing care } \\
\text { practice. }\end{array}$ & $\begin{array}{l}\text { Criar um jogo de } \\
\text { tabuleiro como } \\
\text { gerontotecnologia } \\
\text { voltada à promoção do } \\
\text { envelhecimento ativo }\end{array}$ & $\begin{array}{l}\text { Realizadas entrevistas, } \\
\text { observação participante e } \\
\text { discussões em grupos que } \\
\text { resultou em um jogo de } \\
\text { tabuleiro para idosos. }\end{array}$ \\
\hline
\end{tabular}

A análise mostrou estudos realizados predominantemente na atenção básica ${ }^{30,31,33,36,38,41,42,45-48,50,53}$ e em Universidades ${ }^{22,24,26-28,32,35,37,39,44,51,52,54}$. A maior frequência de atividades desenvolvida pela ABS é esperada, visto estar preconizado na Política $\mathrm{Na}$ - cional de Atenção Básica ${ }^{55}$. Essas unidades estão mais próximas da comunidade e também culturalmente essas ações ainda estão muito restritas ao sistema de saúde. Verificou-se também que as universidades vêm aumentando ações com ido- 
sos, seja por meio das universidades abertas da terceira idade, seja pelos projetos de extensão, o que denota que a questão do envelhecimento está despertando o interesse de tais instituições, fato que pode facilitar outras intervenções semelhantes e influenciar outros setores, bem como aumentar a aproximação dessas com a comunidade. Observou-se pouco envolvimento da comunidade no desenvolvimento das ações. Mesmo assim, alguns dos estudos mencionam a importância deste fator para que os resultados possam beneficiar um número maior de pessoas. Observou-se também escassez de estudos relatando integração de vários setores no desenvolvimento. Isto se deve, entre outros motivos, à noção ainda frequente de saúde restrita às condições biológicas. A importância dos determinantes sociais na saúde e a necessidade de ação conjunta não estão bem entendidas para serem sedimentadas. Essa ainda é uma das principais dificuldades para a efetivação das ações de promoção da saúde ${ }^{56}$.

As oficinas e a formação de grupos foram as técnicas mais utilizadas com uma composição que variou de 8 a 20 componentes com a participação de mulheres prevalecendo. Essa é uma constatação frequente em ações desse tipo por várias razões, as quais incluem a maior resistência dos homens à prática de saúde e participação em atividades para a Terceira Idade; maior proporção de mulheres na população idosa e também porque muitos homens ainda exercem atividades remuneradas para complementação da renda ${ }^{20}$. As discussões envolviam temas de interesse dos participantes, segundo os autores. Essa proposta foi importante para que as ações fossem atrativas e tivessem efeitos positivos, além de propiciar a troca de saberes profissional e popular, como preconizado pela educação popular ${ }^{11-13}$. O princípio da educação popular permeou a maioria das atividades a fim de trabalhar temas diversos como o compartilhamento de histórias de vida, questões práticas de alimentação saudável, atividades físicas, discussão de agravos crônicos, entre outros. Apenas uma ação foi realizada com idosos e adolescentes, a qual buscava o compartilhamento intergeracional de histórias de vida ${ }^{34}$. Esse fato reforça a constatação de que as atividades de educação e promoção da saúde para idosos ainda se limitam quase exclusivamente a esse grupo, podendo inconscientemente promover a segregação etária. Isso se deve, possivelmente, pela dificuldade de reunir vários grupos etários em uma mesma atividade, ou porque prevaleça a ideia de que as ações com idosos devam ser somente para eles, ou ainda pela existência de ideias pre- concebidas, inconscientemente, de que os idosos preferem estar com seus pares, o mesmo pensado para os jovens, fato esse desmistificado em estudos anteriores ${ }^{9,34}$.

Apenas 11 das 33 intervenções foram avaliadas ${ }^{22,23,25,34,37,40,45,48,51,52,54}$. Esse fato sugere que a avaliação ainda não está totalmente sedimentada em atividades de educação e promoção da saúde. Os resultados e os benefícios variam, dependendo do tipo de intervenção realizada, segundo os autores. Em todos, entretanto, é percebido que a promoção da autonomia, da independência e da participação dos idosos está presente, o que as caracterizam como promotoras de saúde e do envelhecimento ativo ${ }^{16,17}$. Observou-se que, em grande parte das ações, os idosos tiveram liberdade para expressar opiniões e participar das ações, muitas vezes conduzindo, eles mesmos, oficinas e atividades, sendo poucas as vezes que ocorreram palestras ou atividades que demandassem certa passividade. Todas faziam alusão à educação, ou à promoção da saúde ou ao envelhecimento ativo. Essa constatação reflete a interdependência ou inter-relação entre EPS, PS relatada por Reis et al. ${ }^{17} \mathrm{e}$ a dificuldade em saber se podem ser consideradas uma metodologia única como proposto por Vasconcelos ${ }^{18}$ ou se a EPS é uma estratégia da PS como pontuado por Pedrosa ${ }^{19}$. Neste estudo, os resultados parecem indicar que a EPS é um meio para o alcance e a promoção da saúde um produto que impulsiona o envelhecimento ativo. No entanto, não existem fronteiras definidas para se saber onde um começa e o outro termina; os três eventos formam um círculo virtuoso de influências e dependências mútuas.

Segundo os autores das ações observadas, houve autopercepção da melhora da memória, da autoestima, a diminuição da ansiedade, maior conscientização quanto à relevância do engajamento no processo de autocuidado, proporcionando-lhes bem-estar, interesse pela vida, ganho de conhecimento e adoção de hábitos saudáveis de vida. Referem, além disso, que as ações ajudaram a prevenir complicações futuras relacionadas às doenças crônicas, melhoras significativas nos componentes da capacidade funcional e na execução das atividades de vida cotidianas, acessos a diferentes opções de atividades físicas, melhorias na saúde mental. Essas últimas constatações, entretanto, carecem de estudos mais aprofundados e de longa duração para serem confirmadas.

Com relação aos benefícios sociais, verificase, de modo geral, o aumento da autonomia e participação ativa dos idosos nas ações, o estímulo à relação interpessoal entre os indivíduos e os 
profissionais envolvidos, a troca de experiências, a ampliação de vínculos afetivos, a criação de novos relacionamentos e a ampliação da rede social de apoio destes idosos. Estes resultados corroboram a importância da educação popular e da promoção de saúde, que consistem em um olhar holístico sobre a saúde para além das necessidades fisiológicas.

Considerando o empoderamento como um dos fatores primordiais das ações de promoção de saúde ${ }^{15}$, todas as referidas ações aqui analisadas parecem alinhadas a esse princípio, o que permite pensar que elas transformam o ambiente e a forma de lidar com questões do cotidiano.

Os resultados demonstram a diversidade de ações de promoção do envelhecimento ativo e os vários benefícios que elas podem oferecer para aqueles que atingiram a velhice. Ainda que haja escassez de estudos com essa abordagem, foi possível apresentar pesquisas que contribuem para o conhecimento e a compreensão desse fenômeno e de seus benefícios na vida dos indivíduos. No entanto, houve pouca discussão sobre a intersetorialidade e a participação da comunidade no planejamento das ações nos estudos analisados.

Os resultados apontam para a possibilidade de replicação das ações estudadas em outros serviços e localidades, como preconiza a revisão bibliográfica integrativa ${ }^{20,21}$, mas poderiam ter um impacto ainda maior se envolvessem mais a comunidade, as escolas, as universidades e outros setores com os serviços de saúde em todos os níveis, como preconizam a educação popular e a promoção da saúde ${ }^{9-13}$ e, assim, possibilitar que as pessoas e a coletividade possam, de fato, ter controle sobre a vida e a saúde e serem atores do próprio destino.

O estudo apresenta certa limitação, principalmente pelo fato de terem sido considerados apenas os artigos disponíveis na íntegra no momento de busca, o que pode ter limitado o número de publicações, principalmente em inglês e espanhol.

\section{Considerações finais}

O presente estudo alcançou os objetivos propostos de apresentar atividades de promoção e educação em saúde voltadas ao envelhecimento ativo. A promoção de uma velhice participativa deve ser incentivada para o atual cenário de maior expectativa de vida da população brasileira. Assim, a disseminação das ações de saúde que propiciam maior autonomia e bem-estar é essencial para o bem-estar comum, bem como motivar a cultura participativa na população e fomentar novas pesquisas nesse campo, principalmente as avaliativas.

A ideia de envelhecimento ativo, proposta pela Organização Mundial de Saúde é oportuna, e deve ser entendida como um processo contínuo da vida para que as pessoas possam desenvolver o hábito do engajamento e da capacidade crítica a fim de tornarem-se atores da própria saúde e da própria vida, bem como influenciar mudanças sociais concretas.

A revisão integrativa da literatura facilitou a reflexão sobre atividades práticas e pesquisas que podem ser replicadas. $\mathrm{O}$ estudo em tela serviu para a observação reflexiva do que tem sido publicado com esse intuito. Serviu também para chamar a atenção para as lacunas existentes como a necessidade de avaliação para mostrar efetividade e que a velhice pode ser uma fase produtiva, desejada e prazerosa da vida.

Para tanto, é necessário que os governos e os gestores de modo geral compreendam o valor da educação e da promoção de saúde para todas as idades, e a importância do combate às injustiças sociais. Dessa forma, os idosos seriam mais participativos e, consequentemente, demandariam menos recursos sociais, passando a exigir, com o poder que podem ter e que possivelmente não estão totalmente cientes, o cumprimento das políticas a eles destinadas.

\section{Colaboradores}


EM Souza, DPP Silva e AS Barros participaram em todas as etapas de forma efetiva para a realização do estudo, cabendo ao autor AS Barros, também a elaboração do fluxograma de busca e organização dos artigos. Os colaboradores contribuíram de maneira fundamental para a realização desse estudo, leram e aprovaram o conteúdo do manuscrito.

\section{Referências}

1. Veras R. Envelhecimento populacional contemporâneo: demandas, desafios e inovações. Rev Saude Publica 2009; 43(3):548-554.

2. Veras RP. Envelhecer no Brasil: a construção de um modelo de cuidado. Cien Saude Colet 2018; 23(6):1929-1936.

3. Instituto Brasileiro de Geografia e Estatística (IBGE). Indicadores Sociodemográficos e de Saúde no Brasil. [publicação online]. Rio de Janeiro: IBGE; 2009. [acessado 2016 Out 28]. Disponível em http://biblioteca.ibge.gov.br/visualizacao/livros/liv42597.pdf

4. Alves JED. Transição demográfica, transição da estrutura etária e envelhecimento. Rev Portal de Divulgação 2014; 40(4):8-15

5. Organização Mundial da Saúde (OMS). Rede Interagencial de Informação para a Saúde. Demografia e saúde: contribuição para análise de situação e tendências. Brasília: Organização Pan-Americana da Saúde; 2009

6. Brasil. Lei n ${ }^{\circ} 10.741$, de $1^{\circ}$ de outubro de 2003. Dispõe sobre o Estatuto do Idoso e dá outras providências. Diário Oficial da União 2003; 3 out.

7. Brasil. Portaria $n^{\circ} 2.528$, de 19 de outubro de 2006 . Aprova a Política Nacional de Saúde da Pessoa Idosa. Diário Oficial da União 2019; 19 out.

8. Brasil. Lei no 8.842 , de 4 de janeiro de 1994. Dispõe sobre a Política Nacional do Idoso, cria o Conselho Nacional do Idoso e dá outras providências. Diário Oficial da União 1994; 5 jan.

9. Souza EM. Evaluation methods in health promotion programmes: the description of a triangulation in Brazil. Cien Saude Colet 2010; 15(5):757-768.

10. Brasil. Ministério da Saúde (MS). Caderno de educação popular e saúde. Brasília: MS; 2007

11. Falkenberg MB, Mendes TPL, Moraes EP, Souza EM. Educação em saúde e educação na saúde: conceitos e implicações para a saúde coletiva. Cien Saude Colet 2014; 9(3):847-852.

12. Freire $\mathrm{P}$, Nogueira. O que fazer: teoria e prática em educação popular. $4^{a}$ Ed. Rio de Janeiro: Vozes; 1989.

13. Freire, P. Educação e Mudança. 12a Ed. São Paulo: Paz e Terra; 1979

14. Vasconcelos EM. A Educação Popular na Universidade. In: Vasconcelos EM, Cruz PJSC, organizadores. A Educação popular na formação universitária: reflexões com base em uma experiência. São Paulo: Hucitec; 2011. p. 15-24.

15. Organização Mundial de Saúde (OMS). Carta de Ottawa 1986. Primeira Conferência Internacional sobre Promoção da Saúde. Ottawa: OMS; 1986. [Acessado 2018 Set 15]. Disponivel em: http://www.bvsms.saúde.gov.br./bvs/publicações/carta_ottawal.

16. Organização Mundial de Saúde (OMS). Envelhecimento ativo: uma política de saúde. Brasília: Organização Pan-Americana da Saúde; 2005.

17. Reis INC, Silva ILR, Un JAW. Espaço público na Atenção Básica de Saúde: educação popular e promoção da saúde nos Centros de Saúde-Escola do Brasil. Interface (Botucatu) 2014; 18(2):1161-1174.

18. Vasconcelos EM. Educação popular: instrumento de gestão participativa dos serviços de saúde. Caderno de Educação Popular e Saúde 2007; p. 19-29. 
21. Whittemore R, Knafl K. The integrative review: updated methodology. Journal of Advanced Nursing. [Internet]. 2005 [cited 2012 Jun 03]; 52(5):546-53. Available from: http://users.phhp.ufl.edu/rbauer/EBPP/whittemore_knafl_05.pdf

22. Assis M. Envelhecimento ativo e promoção da saúde: reflexão para as ações educativas com idosos. Revista APS. 2005; 8(1):15-24.

23. Sancho Castiello MT, Yanguas Lezaun JJ, Díaz Veiga P, Rodríguez Rodríguez P, Pérez Salanova M, Serrano Garijo P, Bermejo García L, Mesa Lampre P, Gómez Pavón J, Ruipérez Canterai I, Gutiérrez B. «Saber envejecer. Prevenir la dependencia.» Un modelo para el diseño de materiales didácticos. Revista Española de Geriatría y Gerontología 2006; 41(Supl. 2):2-16.

24. Assis M, Pacheco LC, Menezes MFG, Bernardo MHJ, Steenhagen CHVA, Tavares EL, Santos DM. Ações educativas em promoção da saúde no envelhecimento : a experiência do núcleo de atenção ao idoso da UNATI. Rev APS 2007; 31(3):438-347.

25. Martins JJ, Barra DCC, Santos TM, Hinkel V, Nascimento ERP, Albuquerque GL, Erdmann AL. Educação em saúde como suporte para a qualidade de vida de grupos da terceira idade. Rev eletrônica enferm 2007; 9(2):443-456.

26. Alencar MDSS, Barros FDO, Carvalho CMRG. Os aportes sócio-políticos da educação nutricional na perspectiva de um envelhecimento saudável. Rev Nutr 2008; 21(4):369-381.

27. Bernardo MHJ, Menezes MFG, Assis M, Pacheco LC, Mecenas AS. A saúde no diálogo com a vida cotidiana: a experiência do trabalho educativo com idosos no grupo roda da saúde. Rev APS 2009; 12(4):504-509.

28. Mazo GZ, Cardoso AS, Dias RG, Balbé GP, Virtuoso JF. Do Diagnóstico À Ação: Grupo De Estudos Da Terceira Idade : Alternativa Para a Promoção Do Envelhecimento Ativo. Rev Bras Atividade Física Saúde 2009; 14(1):65-70.

29. Kuczmarksi MF, Cotugna N. Outcome evaluation of a 3-year senior health and wellness initiative. J Community Health 2009; 34(1):33-39.

30. Combinato DS, Vecchia MD, Lopes EG, Manoel RA, Marino HD, Oliveira ACS, Silva KF. Grupos de Conversa: saúde da pessoa idosa na estratégia saúde da família. Psicologia \& Sociedade 2010; 22(3):558-568.

31. Firmino R, Patrício J, Rodrigues L, Cruz P, Vasconcelos AC. Educação popular e promoção da saúde do idoso: reflexões a partir de uma experiência de extensão universitária com grupos de idosos em João Pessoa - PB. Rev APS 2010; 13(4):523-530.

32. Paiva ACS, Hernandez SS, Sebastião E, Quadros Junior AC, Cury M, Costa JLR, Gobbi LTB, Gobbi S. Dança e envelhecimento: uma parceria em movimento!. Rev Bras Atividade Física e Saúde. 2010; 15(1):70-72.

33. Tahan J, Carvalho ACD. Reflexões de Idosos Participantes de Grupos de Promoção de Saúde Acerca do Envelhecimento e da Qualidade de Vida. Saúde Soc 2010; 19(4):878-888.

34. Souza EM, Grundy E. Intergenerational interaction, social capital and health: Results from a randomized controlled trial in Brazil. Soc Sci Med 2007; 65(7):1397-1409.

35. Wichmann FMA, Areosa SVC, Roos NP. Promoção do envelhecimento saudável: adoção de uma prática multidisciplinar na atenção à saúde do idoso (UNISC). Estud interdiscip Envelhec 2011; 16(2):307-318

36. Andrade TP, Mendonça BPCK, Lima DC, Alfenas IC, Bonolo PF. Projeto conviver: estímulo à convivência entre idosos do Catete, Ouro Preto, MG. Rev bras educ méd. 2012; 36(Supl. 1):81-85.

37. Costa M, Rocha L, Oliveira S. Educação em saúde: estratégia de promoção da qualidade de vida na terceira idade. Rev. Lusófona de Educação 2012; 22:123-140.

38. Patrocínio WP, Todaro MA. Programa de educação para um envelhecimento saudável. Rev Kairós 2009; 15(2):5-27

39. Silveira MM, Pasqualotti A, Colussi EL. Educação gerontológica, envelhecimento humano e tecnologias educacionais: reflexões sobre velhice ativa. Estudos Interdisciplinares sobre o Envelhecimento 2012; 17(2):387-398.

40. Cyarto EV, Dow B, Vrantsidis F, Meyer C. Promoting healthy ageing: Development of the healthy ageing quiz. Australas J Ageing 2013; 32(1):15-20.

41. Patrocinio WP, Pereira BPC. Efeitos da educação em saúde sobre atitudes de idosos e sua contribuição para a educação gerontológica. Rev Trabalho, Educação e Saúde 2013; 11(2):375-394.

42. Mendonça ET, Fernandes L, Aires A, Amaro MO, Moreira TR, Henriques BD, Castro JA, Fernandes VC, Brinati LM. A experiência de oficinas educativas com idosos:( Re) pensando práticas à luz do pensamento Freireano. Rev APS 2013; 16(4):479-484.

43. Morrow-Howell N, Lee YS, McCrary S, McBride A. Volunteering as a pathway to productive and social engagement among older adults. Health Educ Behav 2014; 41(Supl. 1):84S-90S.

44. Sato AT, Batista MPP, Almeida MHM. Programas de estimulação da memória e funções cognitivas relacionadas: opiniões e comportamentos dos idosos participantes. Rev ter ocup. 2014; 25(151-159):130-138.

45. Almeida LFF, Freitas EL, Salgado SML, Gomes IS, Franceschini SCC, Ribeiro AQ. Projeto de intervenção comunitária "Em Comum-Idade": contribuições para a promoção da saúde entre idosos de Viçosa, MG, Brasil. Cien Saude Colet 2015; 20(12):3763-374.

46. Massi G, Berberian AP, Guarinello AC, Lourenço RC, Tonocchi R, Stechman Neto J. Linguagem e envelhecimento: práticas de escrita autobiográfica junto a idosos. Rev CEFAC 2015; 17(6):2065-2071.

47. Patrocinio W. Atividades práticas para o Envelhecimento Ativo. Kairós 2014; 18(19):167-187.

48. Valer DB, Bierhals CCBK, Aires M, Paskulin LMG. O significado de envelhecimento saudável para pessoas idosas vinculadas a grupos educativos. Rev Bras. Geriatr. Gerontol. 2015; 18(4):809-819. 
49. Zanjani F, Downer BG, Hosier AF, Watkins JD. Memory banking: a life story intervention for aging preparation and mental health promotion. J Aging Health 2015; 27(2):355-376.

50. Costa NP, Polaro SHI, Vahl EAC, Gonçalves LHT. Contação de história: tecnologia cuidativa na educação permanente para o envelhecimento ativo. Rev. Bras. Enferm. 2016; 69(6):1132-1139.

51. Inouye K, Orlandi FS, Pavarini SCL, Pedrazzani ES. Efeito da Universidade Aberta à Terceira Idade sobre a qualidade de vida do idoso. Educ. Pesqui. 2018; 44:e142931.

52. Massi G, Wosiacki FT, Guarinello AC, Lacerda ABM, Carvalho TP, Wanderbrooke AC, Cairo NC, Lima RR. Active aging: an intervention-research report. Rev. CEFAC 2018; 20(1):5-12.

53. Mendes NP, Costa NP, Campos ACV, Polaro SHI, Gonçalves LHT. Tecnologia socioeducacional de videodebate para o cultivo do envelhecimento ativo. Esc. Anna Nery 2018; 22(3):e20170427.

54. Olympio PCAP, Alvim NAT. Board games: gerotechnology in nursing care practice. Rev. Bras. Enferm. 2018; 71(Suppl 2):818-826.

55. Brasil. Ministério da Saúde (MS). Política Nacional de Atenção Básica. Brasília: MS; 2012. Série E.

56. Carmo M E, Guizardi FL. Challenges of intersectoriality in public health and social assistance policies: a review of the state of the art. Physis 2017; 27(4):12651286.

\footnotetext{
Artigo apresentado em 27/12/2018

Aprovado em 07/06/2019

Versão final apresentada em 09/06/2019
}

Editores-chefes: Romeu Gomes, Antônio Augusto Moura da Silva 